\title{
CIEN AÑOS DE LA REVOLUCIÓN RUSA. CONMEMORACIÓN DE UN MITO Y MEMORIA COLECTIVA*
}

\author{
Orlando Figes \\ Universidad de Londres
}

\begin{abstract}
RESUMEN: En esta conferencia, el autor arguye cómo el gobierno bolchevique instaurado después de la Revolución de Octubre, dada su falta de legitimidad, debió recurrir casi de inmediato a la mitificación de sus acciones y de la Revolución en general. Este esfuerzo mitificador, persistente en su afán por controlar la memoria colectiva, se mostró luego fundamental para sostener el régimen soviético. Éste cae, de hecho, cuando envejecen las razones que justifican su existencia.

Palabras Clave: Revolución Rusa, bolcheviques, memoria colectiva, colectivismo, socialismo real, mitificación, romanticismo, utopía.
\end{abstract}

Orlando Figes. Doctor en historia por la Universidad de Cambridge. Profesor en el Birkbeck College, Universidad de Londres. Su vasta obra considera, entre otros libros, La Revolución Rusa 1891-1924. La tragedia de un pueblo (1996), El baile de Natacha. Una historia cultural rusa (2002), Los que susurran. La represión en la Rusia de Stalin (2007) y Revolutionary Russia 1891-1991. A History (2014). Email: ubra122@mail.bbk.ac.uk

* Versión traducida de la conferencia que el profesor Figes dio en el Centro de Estudios Públicos el martes 3 de octubre de 2017, en el marco del simposio organizado por Estudios Públicos para conmemorar los cien años de la Revolución Rusa. La revista agradece a Magdalena Merbilhaa su colaboración en organizar la visita del profesor Figes al CEP. 


\section{ONE HUNDRED YEARS ON FROM THE RUSSIAN REVOLUTION. COMMEMORATING A MYTH AND COLLECTIVE MEMORY}

ABSTRACT: In this lecture, the author argues that a lack of legitimacy forced the Bolshevik government inaugurated after the October Revolution to resort almost immediately to mystification of its actions and the Revolution in general. This mystification, insistent in its effort to control collective memory, later proved vital in upholding the Soviet regime, which would fall when the rationale for it grew dated.

Keywords: Russian Revolution, Bolsheviks, collective memory, collectivism, real socialism, mythologizing, romanticism, utopia.

\section{INTRODUCCIÓN}

C omo lo sugiere el subtítulo de mi conferencia, no he venido a exponerles un simple relato sobre la Revolución Rusa, lo que podría resultar muy tedioso. Mi intención es valerme de la conmemoración del centenario de dicho evento para hablar acerca de cómo los rusos tenderán a conmemorar 1917, qué significa la Revolución de Octubre o, en términos más generales, el año 1917 para Rusia y qué puede rescatarse de esa historia de violencia revolucionaria para el presente y el futuro de Rusia. ¿Hay algún pasado rescatable de los eventos de 1917 ?

Para entender cómo Rusia va a enfrentar este aniversario, es necesario comenzar por observar cómo la Revolución ha sido conmemorada, porque si hay una idea que me gustaría que se llevaran de esta conferencia es el hecho de que los rusos no entienden tanto la Revolución y su historia, como el mito de la Revolución Rusa y la historia de ese mito.

Ellos se observan a sí mismos a través de un lente que fabrica leyendas que se remontan al mismísimo año 1917. Por ello, es necesario comenzar por explicar lo que vamos a discutir y observar cómo se fraguó ese mito y se estableció lo que yo describo como una capa sólida de memoria oficial o memoria mítica sobre la Revolución, que predetermina cuál es el uso que puede dársele al centenario que sirva para el futuro.

La idea que quisiera sugerir es que ese mito fue un aspecto medular de la Revolución Rusa desde el primer día, tal como lo ilustra la siguiente imagen (1). 


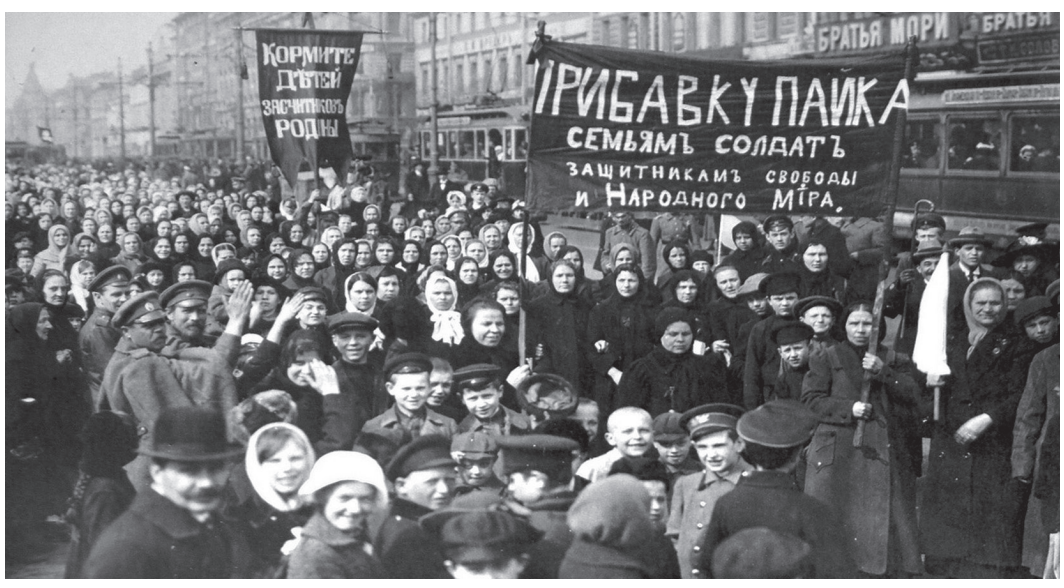

IMAGEN 1. 23 de febrero de 1917 en el antiguo calendario ruso (8 de marzo en el occidental). Mujeres desfilando en el Día Internacional de la Mujer. Un día pacífico previo a la Revolución de Febrero.

No es que las mujeres que desfilaron ese 23 de febrero (u 8 de marzo) supieran que era el primer día de la Revolución, pero la imagen las muestra marchando como solían hacerlo cada 23 de febrero, una jornada importante en el calendario socialista, puesto que era el Día Internacional de la Mujer (el 23 de febrero en el antiguo calendario ruso, antes de que se alineara con el calendario occidental en 1918, correspondía al 8 de marzo en Occidente).

Era un día particularmente cálido, con aproximadamente menos 6 grados, muy superiores a los menos 30 grados que suelen registrarse en febrero en Petrogrado, o San Petersburgo. Eso probablemente hizo que se congregara una mayor cantidad de personas que en otras oportunidades y, como lo muestra la imagen, había mujeres de todas las clases sociales. Se trata básicamente de mujeres provenientes de oficinas, tiendas y empresas textiles del lado de Víborg, la zona norte de Petrogrado. Más tarde, durante ese mismo día, se les unirán muchos hombres. Incluso, podemos apreciar a un señor con un sombrero hongo, lo que transmite una idea de festividad.

Pero la pancarta dice: "Una mayor ración para las familias de los soldados, los defensores de la libertad y la paz del pueblo". Esto nos transmite que ya se ha instalado el mito de que se trata de las familias de los verdaderos patriotas luchando por la paz del pueblo, no la paz del 
zar; no están peleando por la родина о nada parecido, a pesar de que la pancarta de más atrás menciona la palabra родина, que significa madre patria: "Alimentemos a los defensores de la Madre Patria".

Las protestas, entonces, están claramente impregnadas de un lenguaje patriótico, que les confiere un propósito, una dirección y un significado. Durante los días siguientes, el 24 y 25 de febrero, con un clima benevolente, se congregó una multitud cada vez mayor en la avenida Nevski, la principal arteria de Petrogrado, y, como lo hacían por lo general en esa ciudad, dirigiéndose hacia la plaza Znamenskaya o "Plaza de la sublevación", como suele denominarse hoy, donde se encontraba emplazada una estatua ecuestre de Alejandro III, el más autócrata de los autócratas rusos. Era una enorme mole a la que los manifestantes habían apodado hace mucho tiempo como El Hipopótamo, para ridiculizarla.

Los oradores políticos se encaramaron sobre la base de la estatua, proclamaron discursos, aparecieron banderas rojas sobre la estatua y claramente se produjo una apropiación de este símbolo de la autocracia por parte del movimiento de protesta. La policía estaba nerviosa, no sabía cómo proceder, y el 26 de febrero el zar, desde los cuarteles generales de Magiliov, ordenó al general Jabalov, comandante militar del distrito de Petrogrado, disparar si es necesario para reprimir a la multitud. Antes de ese primer disparo, nadie pensaba realmente que se trataba de una revolución. ¿Qué es una revolución? ¿Cuándo un movimiento se transforma en una revolución? ¿Cuándo una protesta callejera se vuelve una revolución?

Alexander Schlatnikov, a la sazón el más alto cargo bolchevique en la capital, escribió a Lenin, que aún permanecía en Zurich: "Son sólo manifestaciones para reclamar una ración de pan; si les dan su ración de pan, los trabajadores volverán a sus hogares". Estaba profundamente equivocado, pues el 26 de febrero algunos de los soldados más jóvenes se negaron a obedecer la orden de disparar sobre la multitud desarmada y uno de los comandantes cogió su arma y se puso a disparar. La multitud exaltada salió corriendo desde la avenida Nevski hacia los regimientos gritando "nos están disparando", y los soldados decidieron acudir en apoyo de la gente. Algunos soldados fueron arrestados, pero al día siguiente hubo un amotinamiento en el que murieron varios altos oficiales. Los soldados salieron a las calles a defender al pueblo contra 
las fuerzas leales al zar y los francotiradores de la policía, y se produjo una especie de guerra civil con muchos enfrentamientos.

Éste es claramente el punto en que se inicia la Revolución Rusa. Lo que era una simple muchedumbre comenzó a organizarse con sus propios símbolos, sus propias ideas de liberación y en función de la topografía de la ciudad. Esta multitud avanzó de forma natural hacia el Palacio Táuride, que se encontraba cerca de algunos regimientos, pero que había sido tradicionalmente foco de manifestaciones porque en él se había reunido la Duma ${ }^{1}$ por primera vez en 1906 y seguía sesionando en aquellos días de febrero.

En una de las alas de ese palacio, algunos miembros de la Duma establecieron un comité para la restauración del orden. Su principal preocupación era recuperar la confianza de los generales en el frente para que no fueran a enviar una fuerza contrarrevolucionaria. Al mismo tiempo, los generales del frente querían tener la seguridad de parte de los líderes de la Duma de que se harían cargo, al contrario de lo que estaba sucediendo en la otra ala del Palacio Táuride, donde los líderes soviéticos estaban formando el sóviet de Petrogrado, con líderes casi exclusivamente socialistas.

Los socialistas no buscaban el poder. Su ideología los llevaba a desear, en primer lugar, la instalación de un gobierno democrático que garantizara todo tipo de libertades. Los líderes de la Duma, en su mayoría liberales, formaron un gobierno provisional que fue anunciado en las puertas del Palacio Táuride ante la incredulidad de muchos de los presentes. ¿Por qué los socialistas se habían tomado el poder? ¿Por qué había un gobierno provisional cuyo líder era el príncipe Georgi Yevgénievich Lvov, un dirigente muy activo durante los años de la guerra y antes? Algunos se decían: “¿Hemos hecho todo esto para remplazar al zar con un príncipe?", porque para ese entonces el zar ya estaba a punto de abdicar.

Por lo tanto, el problema de la legitimidad estuvo presente desde un primer momento, y no debemos perder de vista esa importante idea pues se vuelve muy relevante después de octubre de 1917. Había muchas personas en ese comité temporal de la Duma, entre ellos, Pável

${ }^{1}$ Se conoce como Duma a la asamblea legislativa creada bajo el régimen imperial del zar Nicolás II en 1906. Fue disuelta en 1917. Recién volvió a reconstituirse en 1993, como cámara baja del Parlamento de la Federación Rusa (n. del e.). 
Miliukov, que sería el ministro de relaciones exteriores del gobierno provisional. Él pensaba que debía hacerse todo lo posible para preservar la monarquía, en una suerte de modelo constitucional para salvaguardar la legitimidad del gobierno de la Duma que se iba a formar, así como de las elecciones para la asamblea constituyente que proyectaban.

Como sabemos, eso no sucedió. El zar abdicó y desde un inicio la cuestión de la legitimidad se transformó en un problema agudo para el gobierno. Su principal temor estaba centrado en los soldados, pues eran ellos quienes habían realizado la revolución. Aquí tenemos otro ejemplo de construcción de mito, pues ellos realmente habían llevado a cabo la revolución, sentían que encarnaban la revolución y que debían recibir todo tipo de garantías antes de volver a sus cuarteles. Es por eso que el 28 de febrero, en el salón Catalina del Palacio Táuride, atiborrado de soldados, esta nueva asamblea de sóviets dictaminó cuáles eran las garantías que exigían para que los soldados volvieran a las cuarteles, donde la más importante de ellas fue que los soldados no obedecieran ninguna orden de superiores militares que no contaran con el respaldo de los líderes de los sóviets. De manera que fue como si los soldados, a través del sóviet, ya estuvieran a la cabeza del gobierno provisional y los mandos militares fueran sus rehenes. Volvieron a su guarnición, pero nunca confiaron realmente en el gobierno provisional. Se veían a sí mismos como artífices de la revolución dispuestos a defenderla en cualquier momento si sentían que ésta se veía amenazada.

La siguiente imagen (2) es un ejemplo precoz de retoque fotográfico y de construcción de mitos. Muestra, después de los días de lucha de febrero, a la muchedumbre que comienza a suprimir las insignias y los emblemas monárquicos. Vemos una especie de zapatería, y están sacando el símbolo de los Romanov con la corona sobre la cabeza de un águila. Esto ocurrió en varias zonas de la ciudad y del país. Luego vemos cómo alguien, un soldado quizás, posiblemente también en 1917 - no es posible fechar esta fotografía-, superpuso la imagen de un soldado como diciendo "nosotros estuvimos ahí, es nuestra revolución".

Así, tal como lo he sugerido, la construcción de mitos está presente desde un comienzo y es un componente clave de lo que las personas piensan que están realizando durante esta situación revolucionaria entre febrero y octubre. Gran parte de esa construcción de mitos, de esa ideología de la revolución, estaba contenida en canciones revolucionarias, 


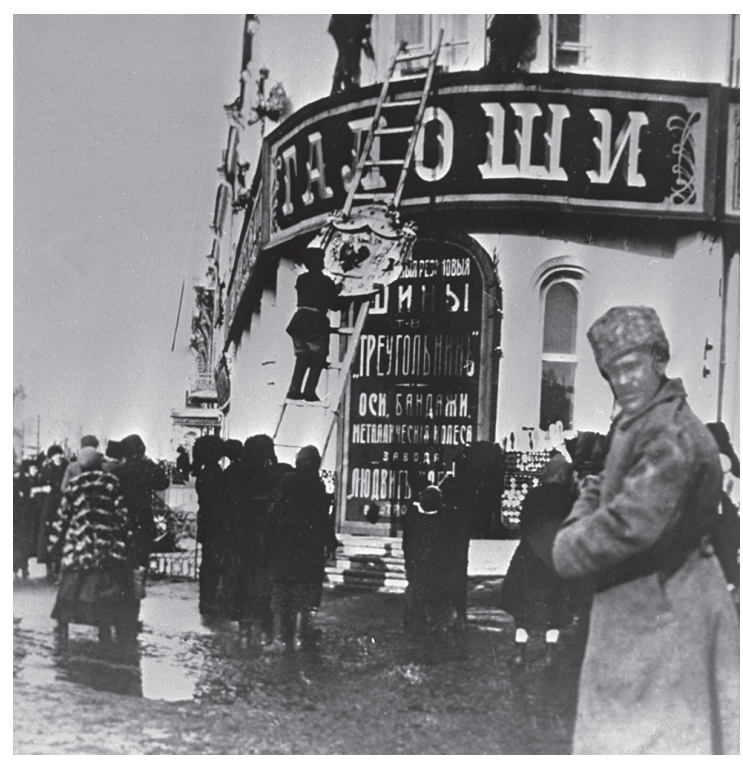

IMAGEN 2. 1917. En la ciudad de Tomsk, dependientes remueven el emblema de los Romanov, un águila con una corona sobre la cabeza, de una zapatería. El soldado, que mira a la cámara, fue montado más tarde sobre la fotografía.

pancartas y eslóganes, como los que pueden apreciarse en la siguiente imagen (3).

En ella se observa la muchedumbre presente en el entierro de las víctimas de la Revolución de Febrero, en marzo de 1917, en el Campo de Marte de Petrogrado. Alrededor de 1.500 personas fallecieron en los enfrentamientos de febrero y aproximadamente 150 fueron enterradas en una fosa común al son de cantos y desfiles, cantos con un gran contenido revolucionario referidos a sus héroes caídos. Se creó una especie de panteón de santos revolucionarios. Algunos de ellos eran suboficiales, personas como Kirpichnikov, que era un revolucionario socialista que había sido uno de los organizadores de la manifestación durante los días de febrero. Nos hemos olvidado de esos nombres, pero en esa época la gente hacía tarjetas postales con el rostro de personas como Kirpichnikov, que habían liderado los alzamientos. Había cantos para ensalzar a estos héroes y consignas como la que vemos en un primer plano de esta foto: "Seremos firmes, defenderemos nuestra revolución de los contrarrevolucionarios", que en aquella primavera era una referencia a los alemanes. En otras palabras, lo que la pancarta proclama es que tenían que seguir 


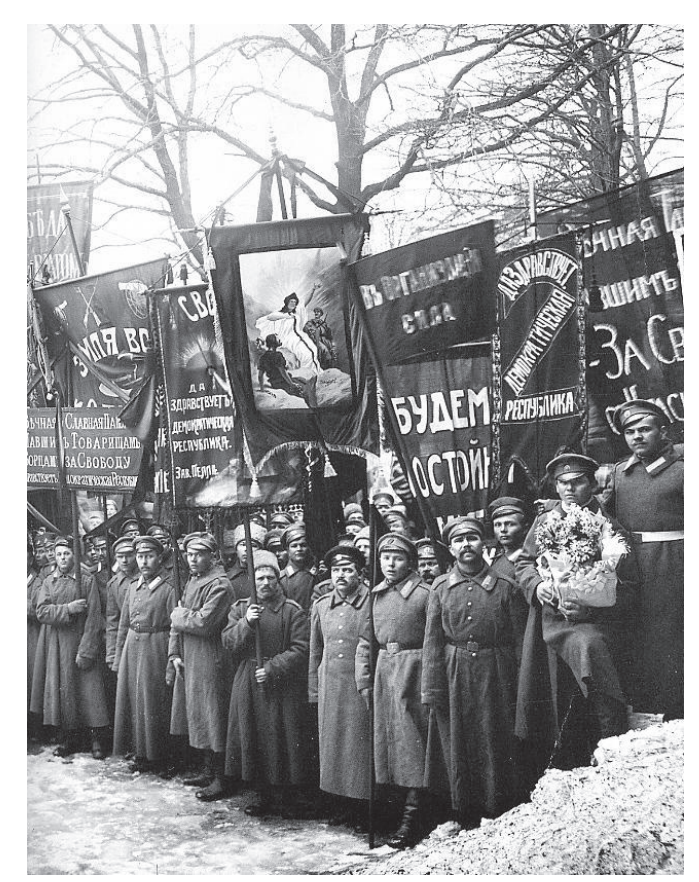

IMAGEN 3. 1917, marzo. Una muchedumbre se hace presente en el entierro de las víctimas de la Revolución de Febrero, en el Campo de Marte de Petrogrado.

luchando, porque si no defendían la revolución contra los alemanes estos invadirían Rusia y volverían a imponer a los emperadores germánicos, y los Romanov y todos sus pares regresarían al poder.

En el primer plano de la fotografía se aprecia una pancarta con una pieza clásica de la iconografía socialista que representa la libertad o, en algunos casos, Rusia, encarnada en una figura femenina, como Marianne en la Revolución Francesa, y con un sol sobre su cabeza. Es una clásica imagen revolucionaria, donde la revolución aparece como una proyección desde las tinieblas hacia la luz, desde las mazmorras hacia las tierras soleadas del socialismo y la libertad. Y esto se transformará en un elemento esencial de la propaganda bolchevique y del realismo socialista en los años treinta. Pero es importante señalar que no son ellos los que lo inventan. Esto proviene de una visión socialista incluso previa a 1917. Por eso, el Primero de Mayo de 1917 se convertiría en una nueva demostración de la eufórica esperanza puesta en la liberación del pueblo, especialmente porque en Rusia coincidiría con Pascua de 
Resurrección. La gente decía Cristo se ha alzado, Rusia se ha alzado, una nueva Rusia está surgiendo, y esto vino a reforzar esta suerte de poder religioso, de mitología que estaba siendo creada por los revolucionarios en torno a la idea de la liberación.

Si nos trasladamos a octubre, el tema de la legitimidad y de la construcción de mitos se vuelve más apremiante, porque los bolcheviques no tenían una auténtica legitimidad y lo sabían. Podían hablar sobre la dictadura del proletariado, podían referirse a la clase trabajadora en términos abstractos, pero sabían - y lo confiesan en los primeros años del poder soviético - que los eventos de octubre habían sido una insurrección, no una revolución. Durante los primeros cinco o seis años, de hecho, se refirieron a la insurrección, y no a la Revolución de Octubre, ya que admitían que no era necesario que fuera una revolución en todo el sentido de la palabra, porque nadie defendía al gobierno provisional en octubre.

La idea que quiero transmitirles es que Kaminov y Zenov advirtieron a Lenin y Trotski en octubre que si se tomaban el poder por la fuerza - idea que Lenin defendía a rajatabla - se verían obligados a gobernar a través del terror y de una guerra civil. Cuando efectivamente se desató la guerra civil, Lenin señaló que ella había comenzado antes de octubre, que la toma del poder había sido un acto preventivo para impedir que los contrarrevolucionarios se hicieran con el poder estatal. Su concepción global de la revolución es que no se requiere una revolución social, sino el poder estatal que luego permitirá gestionar una revolución social a través de una guerra civil.

Así, la guerra civil comenzó cuando se tomaron el poder. El 25 de octubre Kérenski tuvo que escapar, pues todas las líneas telefónicas del Palacio de Invierno fueron cortadas y tampoco contaban con telégrafos. La mitología bolchevique dice que lo hizo vestido de mujer porque les gusta presentarlo como un ser afeminado. No creo que sea verdad, pero sí es verídico que ni siquiera pudo solicitar un taxi, por lo que tuvo que robar un vehículo de la embajada de los Estados Unidos y abandonar la capital en un transporte en el que flameaba la bandera estadounidense, para dirigirse hacia el frente del norte en busca de tropas que lo ayudaran a defender el gobierno provisional contra los bolcheviques. Allí, algunas fuerzas cosacas ya estaban combatiendo a los bolcheviques desde el día siguiente a la toma del poder. 


\section{LA ILEGITIMIDAD Y EL MITO}

Se desató, pues, la guerra civil y los bolcheviques la ganaron hacia 1920 , pero lo hacen con un costo enorme para la economía del país, con la devastación causada por la guerra y el comunismo, que se traduce en una economía planificada y militarizada, y la expropiación de todas las fuerzas del país para alimentar, vestir y armar al Ejército Rojo, que en 1920 cuenta ya con cinco millones de soldados.

Desde febrero y marzo de 1918 deben lidiar con alzamientos de trabajadores que se oponen al racionamiento y a la disciplina laboral que están imponiendo en el país. También se ven enfrentados a cientos de alzamientos campesinos en la primavera, que en 1920 culminan en revueltas campesinas en todo el país. Incluso son abandonados por quienes constituían su honor y gloria, como Trotski los había denominado en 1917, los marinos de Kronstadt, que habían liderado el alzamiento en julio de 1917 y que habían jugado un rol clave en la insurrección de octubre. Pues bien, en 1921 estos marinos están hartos con los bolcheviques y organizan un gran amotinamiento que es aplastado con sangre por los bolcheviques, que se abalanzan sobre ellos cruzando el hielo, bombardeando la base naval de Kronstadt, arrestando a los que aún no habían logrado matar o evitando que escaparan a Finlandia. Y, por supuesto, también enfrentan problemas a nivel nacional, como el hecho de que tienen que reconquistar Ucrania y reconquistar gran parte del antiguo imperio ruso. En suma, tienen problemas de falta de legitimidad.

Si miramos la siguiente imagen (4), del 7 de noviembre de 1919, podemos ver la Plaza Roja, los muros del Kremlin y un desfile.

Pero el desfile no son las masas. Son los soldados del Ejército Rojo y los mismos bolcheviques. En otras palabras, los bolcheviques, una vez concluida la guerra civil, se enfrentan al problema de crear un mito fundacional que asiente la idea de que la revolución y la guerra civil eran movimientos populares, que los bolcheviques habían accedido al poder, si no por los votos, sí como representantes de un extendido movimiento social. Ya sabemos que la última votación fue la de la asamblea constituyente, realizada justo después de la toma del poder por parte de los bolcheviques, el último Parlamento genuinamente democrático de Rusia. En esa elección, celebrada a mediados de noviembre de 1917, los bolcheviques obtuvieron sólo el 10 por ciento de los votos y optaron por cerrar la asamblea constituyente por la fuerza. 


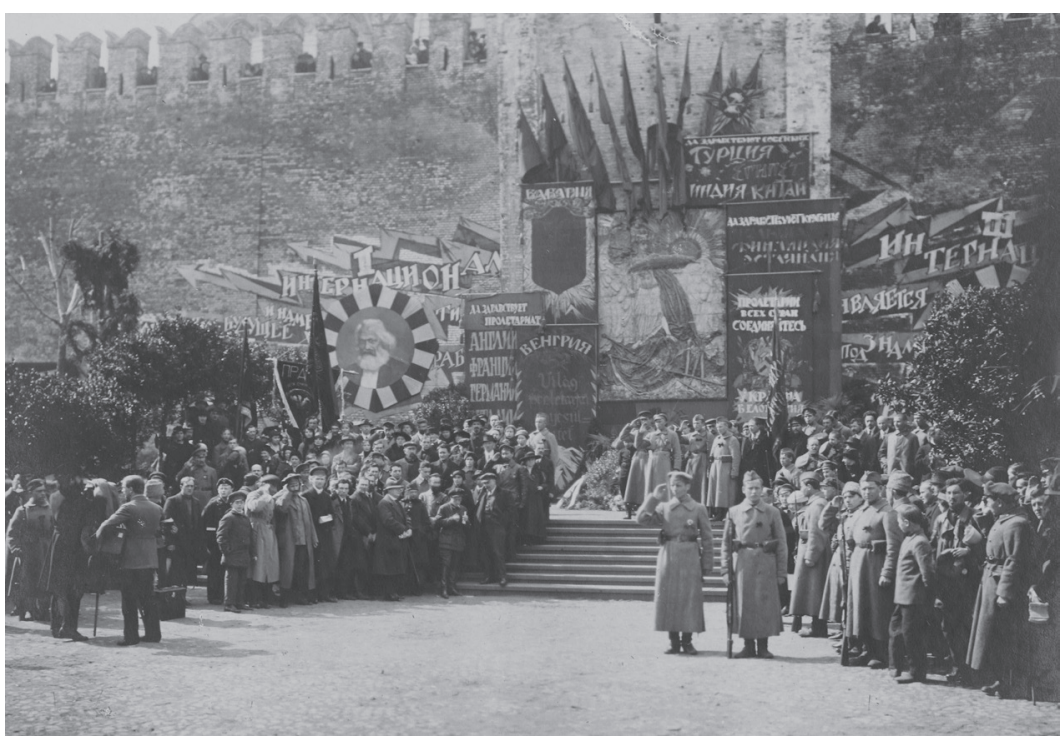

IMAGEN 4. 7 de noviembre de 1919. Desfile conmemorativo de la Revolución de Octubre en la Plaza Roja de Moscú, frente a los muros del Kremlin.

Puesto que tienen ese problema de legitimidad, los bolcheviques deben recurrir a la propaganda, a la construcción de leyendas, para crear un mito fundacional que describa la Revolución de Octubre como un evento masivo y la guerra civil, como una causada gracias al movimiento de masas que los respaldaba.

En 1920, el gobierno produce una recreación "teatral" de los eventos de 1917 que culmina en la toma del Palacio de Invierno. La realizan en la Plaza del Palacio de Petrogrado, como aún se denomina el lugar, y concurre un elenco de miles de personas y un público de más de 100 mil personas que contemplan la escena. Todo es convenientemente filmado. ${ }^{2}$ En esta recreación, como podemos ver, figura Kérenski deambulando como una especie de Napoleón al que se intenta pintar como un personaje pomposo y tonto. Kérenski siempre había querido ser un actor y hacía discursos muy dramáticos. Muchas veces se desmayaba en el momento preciso para darles más efecto a sus palabras. Vemos también que, por algún motivo, el gobierno provisional de 1917 está apoyado por personas que

${ }^{2}$ Parte de esta filmación puede verse hoy en YouTube, bajo el título de "Storming the Winter Palace (1920)": https://www.youtube.com/watch?v=fLihunxEzwE. 
parecen provenir del siglo dieciocho. Luego tenemos a los especuladores bancarios, unos personajes con bolsas de dinero sacando provecho de la Revolución, y a continuación un texto que dice: "Bajo el yugo de los capitalistas". Puede verse también a los trabajadores oprimidos saliendo de sus mazmorras, trabajando para los banqueros capitalistas, sufriendo tal como sus mujeres sufren, todo en una especie de gran desfile de masas. Más tarde aparecen más cortesanos de Kérenski, tratando de sacarle el dinero a la gente: son los capitalistas. Luego aparece el alzamiento de julio de 1917, cuando los marinos de Kronstadt y un grupo de trabajadores trataron de forzar a los sóviets a que se tomaran el poder, y éstos no lo hacen porque estaban aún liderados por los revolucionarios socialistas y los mencheviques, y los bolcheviques no sabían si tenían que brindarles o no apoyo. El cortometraje sigue con una pancarta que dice "Larga vida a los campesinos y los soldados", y después viene la catástrofe, el colapso. Toda la toma del Palacio de Invierno es retratada como un gran movimiento de masas, en el que el pueblo resulta triunfante.

\section{LENIN Y EL DÉCIMO ANIVERSARIO}

El mito o la idea de que octubre fue un evento masivo, un evento popular, nunca se acomodó muy bien con el otro componente del mito revolucionario soviético; a saber, que éste fue producto del genio de Lenin. Es difícil quedarse con ambas versiones, pues o se trata de una revolución de las masas o se trata de la revolución de Lenin. Ahí es cuando entra Eisenstein, quien realiza su famosa película Octubre, para el décimo aniversario de la Revolución en 1927, y soluciona muy bien este dilema en una famosa escena (imagen 5). Es el momento cuando Lenin regresa de Zurich en un tren blindado. Recuerden que los alemanes querían enviar a Lenin y a otros socialistas contrarios a la guerra de vuelta a Rusia y los suben en este tren blindado que atraviesa todo Escandinavia para llegar a la estación de Finlandia, en San Petersburgo. Sabemos por los registros históricos que los alemanes siguieron financiando a los bolcheviques hasta 1918. Lenin sale de este tren y, según la película de Eisenstein, se encarama sobre el carro blindado para arengar a las masas reunidas. Eisenstein transmite entonces, de manera brillante, la idea de la unión de Lenin y las masas con unos proyectores inexistentes, un haz de luz que hace un barrido sobre la muchedumbre 


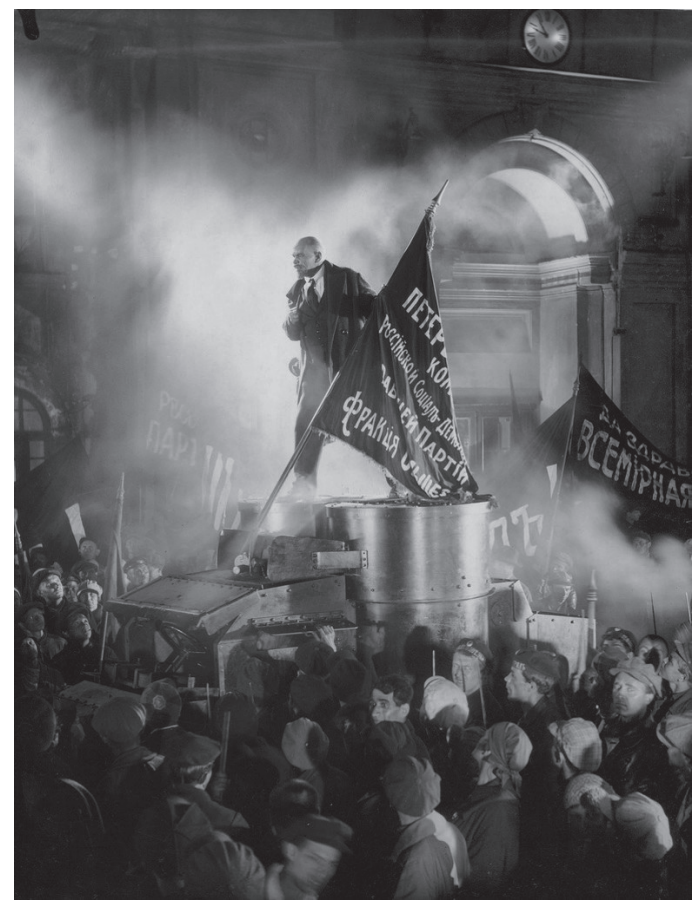

IMAGEN 5. 1927. Famosa imagen de la película Octubre, dirigida por Serguéi Eisenstein, donde se ve a Lenin, sobre el tren blindado que lo trajo desde Zurich, dirigiéndose a las masas reunidas.

fundiéndola con Lenin, como si se hubiera producido una especie de exaltación religiosa que opera como fusión entre Lenin y el pueblo.

Esta película es probablemente la pieza más famosa de construcción de mitos sobre la Revolución. Fue encargada por la Comisión del Aniversario de Octubre de la Presidencia del Comité Central, que es básicamente la instancia ejecutiva de todos los sóviets rusos, comisión que también le encargó a Pudovkin, un director vanguardista al igual que Eisenstein, realizar el largometraje El fin de San Petersburgo, en el que predomina la idea de una revolución masiva. En su película, Eisenstein no utilizó actores profesionales, sino que recurrió a gente común y corriente; por ello, la persona que hace de Lenin es un pésimo actor pero se le parece físicamente, un trabajador denominado Mikanderov. Los habitantes de Leningrado también son utilizados en la película, y el comisionado que encargó este trabajo, Nikolái Podvoiski —un miembro prominente del Comité Militar Revolucionario-, como 
fue un personaje importante en la insurrección de octubre, se encarna a sí mismo en el largometraje.

La culminación de esta película, con su idea de que octubre fue un evento masivo, es el asalto del Palacio de Invierno con la famosa escena en la que Eisenstein muestra al pueblo, representado literalmente por decenas de miles de personas, asaltando el palacio, ingresando con sus armas, encaramándose sobre las rejas principales y ascendiendo por la escalera Jordana hacia el cuarto Malaquita, donde los restantes ministros del gobierno provisional estaban esperando su arresto. Es una operación militar con armas y disparos.

Ahora bien, en primer lugar, en los hechos la multitud no ingresó por la reja; segundo lugar, no subieron por la escalera Jordana: lo hicieron por la escalera de Octubre, como se denominó posteriormente, pero Eisenstein quería utilizar esta gran escalera procesional. No creo que toda la multitud retratada en la película haya efectivamente tomado parte en la insurrección. Trotski cifra en aproximadamente 20 a 25 mil el número de participantes activos en la insurrección de octubre, y creo que es una estimación razonable si se cuentan todas las personas que estaban en las calles, como las patrullas, los guardias rojos, las personas en actitud de defensa de las instalaciones importantes. El verdadero asalto del Palacio de Invierno, que fue dirigido por Vladímir Antónov-Ovséyenko, consistió más en un arresto domiciliario que un asalto. No había realmente nadie defendiendo a los ministros del gobierno provisional. Había unos pocos cosacos y cadetes, pero no habían recibido alimentos en todo el día y a las 10:40 horas de la noche, cuando comenzó el asalto, la mayoría había regresado a sus hogares por comida. Así es que fue más parecido a un arresto domiciliario y es muy probable que durante la filmación de la película se hayan causado más destrozos al palacio que cuando fue asaltado. En efecto, en 1927, cuando realizaron la película aún existía uno de esos pequeños personajes que trabajan en el palacio recogiendo colillas de cigarros y sacándoles brillo a los muebles y que probablemente llevaba 30 años realizando esa tarea. Él le dijo a Eisenstein: "Tu gente, los bolcheviques, cuando vinieron la primera vez, eran más ordenados". Entonces se trata de una fantástica construcción de mito, que persuadió a la mayoría de la gente, incluso en Occidente, de que realmente se había tratado de un levantamiento popular.

Esta película estaba programada para el aniversario de 1927, pero nunca vio la luz en esa fecha. Adivinen por qué. Porque en gran parte 
del material aparecía Trotski, quien había sido el cerebro del Comité Militar Revolucionario y, desde muchos puntos de vista, la persona que había liderado el sóviet de Petrogrado. Posiblemente desempeñó un papel más importante que Lenin en la organización de la insurrección, si bien no en la decisión de llevarla a cabo. Pero para 1927 había caído en desgracia, había sido expulsado del partido y enviado al exilio, por lo que el pobre Eisenstein tuvo que pasarse otro año recortando a Trotski y procurando que la película conservara aún alguna coherencia. Por lo tanto, sólo fue exhibida en 1928 en unas pocas salas, y en 1933 la película fue lisa y llanamente censurada, porque no mostraba a Stalin, y ello por una razón muy simple: Stalin no había jugado ningún rol relevante en la insurrección de octubre. Un cronista menchevique lo denominó "el borrón gris" de la Revolución, porque nadie podía recordar lo que había hecho. Por ello, para el vigésimo aniversario de la Revolución en Octubre, en 1937, un año bastante ominoso, Stalin encargó a Mijaíl Romm una película titulada Lenin en octubre (imagen 6). Es muy cómica. Básicamente, muestra a Lenin como un títere cuyas acciones están controladas por el auténtico genio de la Revolución, el hombre que está de pie a sus espaldas: Stalin.

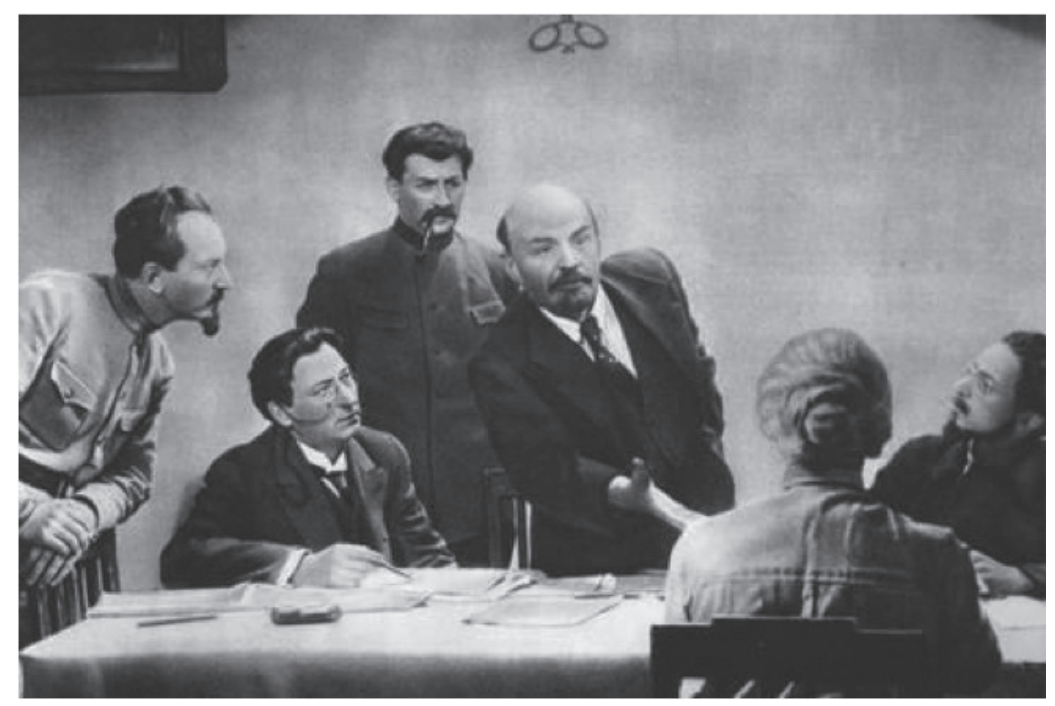

IMAGEN 6. 1937. Fotograma de la película Lenin en octubre, dirigida por Mijaíl Romm. En ella Lenin aparece como un títere cuyas acciones son controladas por el auténtico genio de la Revolución de Octubre, el hombre a sus espaldas: Stalin. 


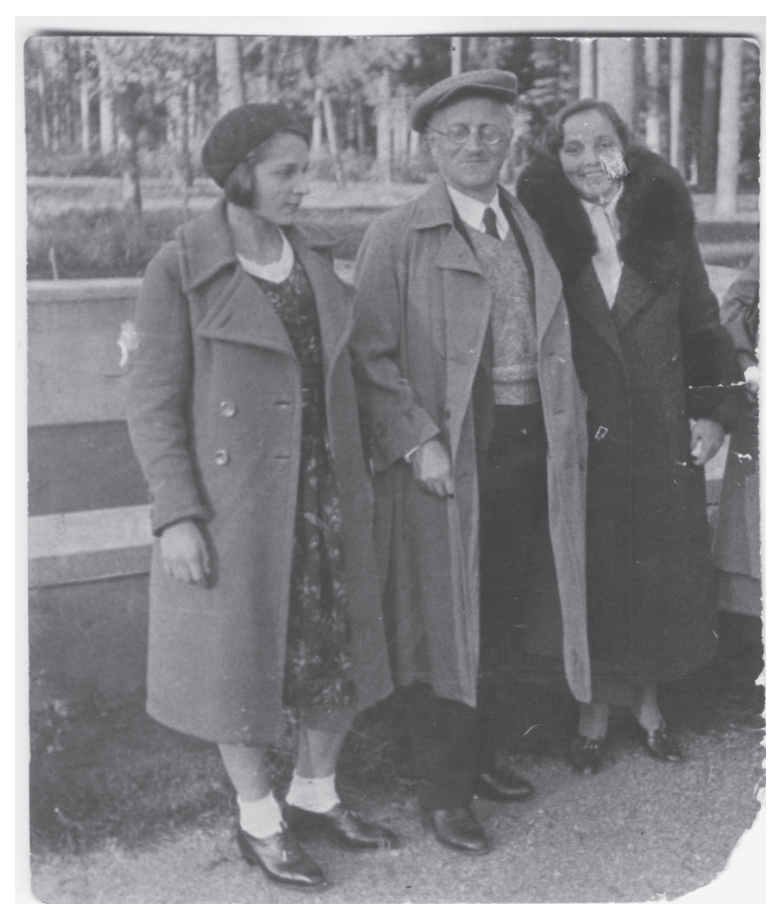

IMAGEN 7. Vladímir Antónov-Ovséyenko, líder del "asalto" al Palacio de Invierno en octubre de 1917, aparece aquí retratado junto a su segunda esposa y su hija. El 4 noviembre de 1937, tres días antes de la celebración del vigésimo aniversario de la Revolución, fue arrestado y, más tarde, ejecutado.

Como ustedes saben, 1937 era un período de terror en el cual gran parte de la historia soviética es reescrita. El hombre que lideró la insurrección de octubre, el que arrestó a los ministros del gobierno provisional, Vladímir Antónov-Ovséyenko, es retratado en la siguiente imagen (7) en medio de un grupo que incluye a su segunda esposa y su hija. El 4 de noviembre de 1937, tres días antes del vigésimo aniversario de la Revolución, Antónov-Ovséyenko es arrestado y ejecutado. Su esposa es arrestada el mismo día y enviada al gulag.

\section{LA SEGUNDA GUERRA Y LA RENOVACIÓN DEL MITO}

La Segunda Guerra Mundial cambió por completo el sentido del mito de octubre. Me atrevo a decir que el discurso de Stalin en la Plaza Roja del 7 de noviembre 1941, para el desfile del Día de la Revolución, 
fue probablemente la última vez en que se citó o movilizó la idea de Octubre y de la guerra civil con fines míticos, en servicio de los bolcheviques. Se le había recomendado a Stalin no autorizar el desfile el Día de la Revolución porque los alemanes estaban bombardeando intensamente la ciudad de Moscú y existía el peligro de que fueran alcanzados por las bombas, pero él consideró importante realizarlo debido a su significado simbólico. Por lo tanto, se llevó a cabo el desfile frente al mausoleo de Lenin, pero no sobre éste, sino en una estación subterránea del metro por razones de seguridad. Stalin realizó un discurso que es difundido masivamente por radio e impreso en todos los periódicos disponibles. En él evoca la memoria de 1918 y el primer aniversario de la Revolución: "Ustedes saben, en la guerra civil estábamos rodeados por catorce fuerzas hostiles, por los poderes capitalistas occidentales y no contábamos con un ejército, no teníamos nada pero superamos la prueba y salimos victoriosos. Debemos recobrar nuevamente ese espíritu para combatir ahora".

Así, en 1945 y tras la victoria soviética, el sentido ha cambiado completamente, porque lo que se celebra ahora no es la revolución sino la victoria. Es el hecho de que la Revolución ha creado una sociedad, un poderío industrial y militar capaz de salvar a la humanidad y derrotar a Hitler. Eso es lo que se comienza a conmemorar y que se transforma en el nuevo mito fundacional de la Unión Soviética de la postguerra. La victoria contra el nazismo es utilizada para justificar todo lo sucedido desde 1917. Y éste es un mito que solía escucharse mucho y aún se escucha a menudo, no sólo entre los izquierdistas occidentales, sino también entre los liberales y conservadores; a saber, que Stalin construyó los tanques que derrotaron a Hitler. La idea de que la victoria de 1945 justifica todo lo realizado desde octubre de 1917 es clave para el mito fundacional de la Unión Soviética, porque los tanques y toda la maquinaria que derrotó a Hitler estaban basados en la revolución industrial que había sido organizada por el partido, hecha posible por la colectivización. Y el terror que acompañó este proceso es algo que debemos aceptar porque los logros globales de la industrialización soviética son muy significativos.

Ahora bien, la gente hablaba sobre el terror en 1945, pero éste es el mensaje que se transmitía desde las esferas oficiales. La mayoría de las personas que tenían un recuerdo directo de la Revolución y de la guerra 
civil, probablemente, estaban muertas o eran muy ancianas, por lo tanto ya no tenía mucho sentido seguir apelando a esa memoria. Ésta podía seguir existiendo en el trasfondo, pero para la población que sobrevive a la guerra es mucho más significativa la idea del sacrificio, sacrificio por el país, por los esfuerzos bélicos, por la victoria, y ese sacrificio en sangre es una suerte de vino sagrado de la Revolución. Posee una fuerza emocional muy poderosa debido al sufrimiento experimentado por el pueblo soviético. Muchas personas perdieron a sus padres, hijos, hermanos, esposas; muchos sufrieron y ese sufrimiento colectivo les permite a las personas darles un sentido a sus vidas identificando su propio sufrimiento con el logro colectivo de la victoria en la guerra. Me atrevería incluso a decir que después de 1945 la memoria de la Revolución ya no es significativa, ya no constituye la memoria principal de la gente en los años de postguerra. De ahí en adelante, todo gira en torno a la guerra.

Puedo ilustrar esta idea con una anécdota. Cuando fui por primera vez a Moscú en 1984 como estudiante de postgrado pensé que aún podía encontrarme con individuos que me relataran experiencias de la guerra civil, que era mi investigación de entonces, y contacté a algunas personas que estaban un poco nerviosas de hablar conmigo sobre temas históricos (estábamos en 1984, no en 2004). A pesar de que no me contaron nada muy revelador, lo que más me llamó la atención fue que todo giraba en torno a la Segunda Guerra Mundial. Los recuerdos de la guerra habían sepultado cualquier otra memoria del mito revolucionario original.

\section{EL COLAPSO DEL MITO}

Para los años sesenta y setenta, esta militarización del mito revolucionario y su leyenda está muy marcada en el pueblo soviético. La siguiente imagen (8) es del desfile del Día de la Revolución en la Plaza Roja, el 7 de noviembre de 1972, para el aniversario número 55 de la insurrección. Aunque los héroes de la guerra civil se utilizan como telón de fondo en lo fundamental, ya está configurado lo que venimos observando desde los años sesenta y seguimos viendo en los setenta, ochenta. Todos hemos sido testigos de las imágenes en la televisión, el reportaje del Día de la Revolución y no es un evento precisamente revolucionario. 


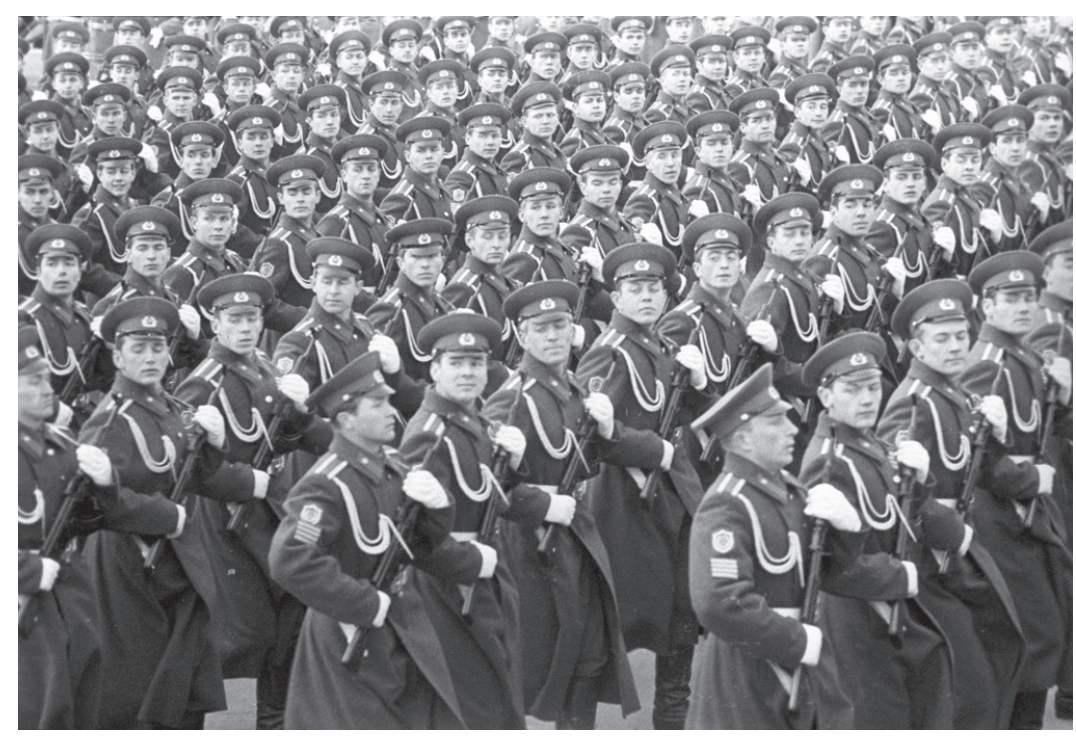

IMAGEN 8. Moscú, 1972. Cadetes de la Academia de Comandos de Guardias de Altas Fronteras de la KGB desfilan en el aniversario número 55 de la Revolución de Octubre por la Plaza Roja. Créditos: Lev Polikashin, archivo RIA Novosti, CCBY-SA 3.0.

Su énfasis, más bien, es el poderío militar soviético, los misiles nucleares y todo lo que lo acompaña. ¿Qué está sucediendo y qué significa?

Pienso que la necesidad de reinventar la revolución en este contexto militarizado y luego la crisis de este mito y el final del poder soviético es, esencialmente, un problema generacional. Como lo señalo en mi libro más reciente, Rusia Revolucionaria, 1891-1991, mi intención fue mirar la Revolución en un período extenso, porque quise pensar en qué es una revolución valiéndome de las palabras de los propios líderes soviéticos, que aseguraban estar continuando la Revolución de Lenin. Y creo que fue útil pensar en esos términos porque tal vez sólo podamos explicar las acciones revolucionarias de Gorbachov de la perestroika y la glasnost si pensamos que se trataba genuinamente de un leninista. Si no hubiera sido un revolucionario no hubiera intentado algo tan osado.

Esto me llevó también a pensar cuánto tiempo puede durar una revolución. Y llegué a la conclusión de que sólo puede durar tres generaciones, porque si en 1945 la memoria de 1917 y de la guerra civil realmente tiene poca relevancia, en los años ochenta, aplicando la misma 
lógica, para los jóvenes soviéticos la guerra tiene poca o ninguna relevancia. Puede que aún haya ancianos desfilando el Primero de Mayo, el Día de la Aviación o en cualquier conmemoración de veteranos que uno pueda pensar, con todas sus medallas, pero a los jóvenes no les interesa, lo ven como una historia anticuada. Están más interesados en los Beatles y los Rolling Stones y todo lo que Occidente pueda ofrecerles. Ya no quieren seguir escuchando estas viejas historias. Creo que esto pone en aprieto al sistema soviético, porque saben que el mito de Octubre y el de la guerra ya no tienen el mismo poder de imantación, ya no ejercen la misma fuerza. Entonces realizan todo tipo de informes sobre el problema de la juventud, la degeneración de la juventud, que la juventud ya no está activa y qué se yo. Y bajo Brézhnev adoptan el estilo basado en las promesas económicas, y, al igual que en 1963, el PCUS elabora un programa que contiene promesas como, por ejemplo, que superarán el desarrollo de Occidente, idea que tendrá corta vida.

Bueno, ¿qué ha sucedido desde 1991? Con el colapso del comunismo creo que el legado de esta mitología se transformó en un tema muy complejo porque generaba muchas divisiones. Naturalmente, el Partido Comunista seguía siendo el partido más grande y organizado del país y aún representaba al sector más anciano de la población, pero los jóvenes, que estaban hartos, no querían saber nada del comunismo. Muchos se volvieron monarquistas, nacionalistas, fascistas. Surgió todo tipo de ideas para intentar llenar el vacío creado por el derrumbe del comunismo, y a Yeltsin le correspondió la ardua tarea de tratar de unir a una nación bajo un esquema federal. El problema al que se enfrentó es que Rusia nunca había sido una nación, pues se había desarrollado como un imperio. El país no tenía un sentido propio de nación y sigue careciendo de él. Tiene una visión más bien imperialista de sí mismo, como pudimos comprobarlo con la invasión de Crimea. Necesitaban nuevos símbolos para intentar unificar a la nación. No podían volver a los símbolos de 1917 ni querían volver a los símbolos imperiales.

Intentaron crear nuevos símbolos, pero no generaron ninguna adhesión. Se deshicieron del Día de la Revolución, el 7 de noviembre, y trataron de remplazarlo con algo que denominaron Día de la Reconciliación o algo así, pero nadie entendió su propósito y se asumió simplemente como un feriado más. Luego se hizo esta mezcla posmoderna de símbolos e ideas en la que, por ejemplo, la gente de Leningrado votó 
por renombrar su ciudad como San Petersburgo, pero todavía estaba ubicada en el distrito de Leningrado. Así, había un municipio con la bandera de San Petersburgo y la bandera de Rusia que a estas alturas ya era la nueva bandera rusa, pero a su costado estaba la bandera roja con la hoz y el martillo. En cuanto al himno nacional soviético, lo suprimieron y luego lo restituyeron, pero sin las letras alusivas a los soviéticos. Hubo mucha confusión y parte de ella persiste.

Es un problema con el que nunca han sabido realmente lidiar $\mathrm{y}$ parte importante de él es la memoria colectiva. Nunca hubo realmente suficiente tiempo en la era de Gorbachov y Yeltsin para que una memoria colectiva floreciera libremente y permitiera redefinir la identidad de Rusia y en qué había consistido la Revolución. En realidad, durante el período de la glasnost prácticamente no se discutió sobre la Revolución. Todo estaba centrado en la era de Stalin y sus atrocidades. No hubo mucha discusión sobre qué significó la Revolución; no se preguntaron: ¿fue el momento en que se fundó el Estado soviético?; ¿cómo vemos el futuro? Había cierta confusión e ignorancia, porque la gente básicamente había sido educada en las escuelas soviéticas, bajo la propaganda oficial y no sabía mucho acerca de lo que se conocía como las lagunas de la historia soviética. La gente ni siquiera sabía mucho acerca de la insurrección del Kronstadt, las revueltas campesinas u otros hitos relevantes. Había muchos pasajes de su historia que nunca les habían sido enseñados y que ignoraban casi por completo.

Así las cosas, cabe preguntarse qué va a suceder en noviembre de 2017, fecha en que Rusia conmemora el centenario de 1917. Por razones que espero haber dejado claras en esta conferencia, la fecha no es motivo de celebración. No es un momento con el cual el gobierno quiera lidiar en absoluto y la sociedad en su conjunto no tiene claridad respecto a qué carácter darle. No hay una visión consensuada sobre 1917 $\mathrm{y}$, por ende, pienso que se optará por un evento muy discreto. Desde un comienzo, Putin dejó en claro que ésa era su idea. En 2014, cuando se le preguntó su opinión sobre lo que sucedería en estas fechas respondió que ello requeriría algo así como "una profunda y objetiva evaluación profesional". Luego, en diciembre de 2016, el gobierno anunció la formación de una comisión liderada por Anatoli Tarkunov, director del Instituto Estatal de Relaciones Internacionales de Moscú, un think tank que organiza conferencias bastante aburridas. De hecho, yo debería estar 
allá esta semana, pero en lugar de ello preferí venir aquí. El gobierno decidió, entonces, que no se involucraría y en marzo de este año uno de los portavoces de Putin señaló a The New York Times que el gobierno no participaría en la conmemoración. En consecuencia, no hay una visión oficial.

Si volvemos a reflexionar sobre ello, las razones son bastante claras. En primer lugar, es un tema que genera divisiones y sobre el cual no hay consenso. En la prensa rusa hay muchos artículos sobre cómo los rusos están aún combatiendo ideológicamente la guerra civil, y así están los descendientes de aquellos que creen en la causa del Ejército Blanco y los descendientes de aquellos que creen en la causa del Ejército Rojo. Para algunos, la Revolución fue el comienzo de una gran civilización, la Unión Soviética, con la que aún se identifican, y para otros fue una catástrofe nacional, el fin del imperio ruso, el momento en que Rusia se vio obligada a abandonar la guerra. Y para muchos, en la extrema derecha de esa visión nacionalista, fue como una puñalada en la espalda y responsabilizan de esta traición a los masones, a los judíos, a los extranjeros.

Putin se mueve de alguna forma en las dos bandas. Por un lado, se alinea con los comunistas, como cuando hubo un intento por sacar el cuerpo de Lenin del mausoleo y dijo que eso sería negativo, porque sería como decirle a mucha gente que había creído en la Revolución que su sacrificio había sido en vano. Por otro lado, es conocida su admiración por, entre otros, el general Denikin del Ejército Blanco, la principal fuerza contraria a los bolcheviques. Y en los últimos años, también, se han conmemorado con estatuas a varios generales del Ejército Blanco, algo que en alguna medida comenzó con Putin. En 2005, él organizó la repatriación de los restos mortales del general Denikin, refugiado y fallecido en los Estados Unidos, gracias a lo cual fue enterrado en una gran ceremonia religiosa en el Monasterio Donskoi de Moscú.

La segunda razón es que la Revolución es el último problema con el que Putin quisiera tener que lidiar en este momento. La revolución lo aterroriza, especialmente la revolución en Ucrania. Es algo que no quisiera ver replicado en Moscú, y ya sabemos que el gobierno siente que es un fenómeno del cual se salvó milagrosamente luego de las manifestaciones masivas que tuvieron lugar en la plaza Bolótnaya, de Moscú, en 2013.

Pero creo que la razón fundamental es que finalmente resulta muy poco claro qué lección pueden extraer los rusos de 1917. Cuando los 
franceses celebraron el centenario de su Revolución, en 1889, construyeron la Torre Eiffel. Era el símbolo de los valores republicanos, y ello se dio en un momento en que el gobierno francés, bajo la Tercera República, estaba muy confiado respecto de los valores republicanos y democráticos del sistema y reivindicaba su legado, no sólo a partir de la Revolución Francesa, sino que también de la Ilustración que la sustentaba. Antes de la celebración del centenario se realizaron conmemoraciones de Rousseau, Voltaire y otros. Era pues un momento de gran confianza en los valores de la Revolución. Pasaron por alto el terror de la Revolución, pero sabemos que todas las revoluciones conllevan cierto grado de terror que debemos obviar si queremos transformarlas en un referente nacional. Pues bien, los rusos no pueden hacer eso. Creo que no hay nada que puedan extraer de 1917, por lo menos de octubre. Desperdiciaron la oportunidad en febrero, momento del cual podrían sacar muchas enseñanzas. El período entre febrero y octubre de 1917 tiene un enorme potencial, grandes posibilidades políticas, pero es un momento de poder popular y eso es exactamente lo que el gobierno desea evitar.

También podría decirse que la mayoría de los rusos están hartos de la Revolución y que no quieren celebrarla de ninguna forma. ¿Pero qué otra lección podrían extraer los rusos de 1917? ¿El socialismo? Ya no es un Estado socialista. ¿La justicia social? Es uno de los Estados con mayor desigualdad, ciertamente en Europa. ¿La industrialización? Han construido fábricas que ahora están en ruinas. ¿El internacionalismo? No son internacionalistas. Son nacionalistas. Cada poder para sí mismo, en lo que a los rusos concierne.

Por lo tanto, es muy poco lo que pueden extraer como lección y creo que, a fin de cuentas, se quedarán con algo en línea del mensaje que ha transmitido Vladimir Medinski, que es el ministro de Cultura, que se llama a sí mismo historiador, aunque tengo dudas de aquello. Él ha estado escribiendo respecto a que la Revolución fue una tragedia, aunque no en el sentido en que utilizo esa palabra en mi libro, que es el sentido griego del concepto, donde todo puede suceder y es la historia de las personas la que precipita su perdición. Para Medinski, las revoluciones son intrínsecamente malas, implican sólo destrucción, división, guerra civil. Él sostiene que lo que debemos aprender de las revoluciones es que son nefastas y que lo que se requiere es un gobierno fuerte, y 
que los hechos de 1917 muestran es que es una muy mala idea entregarles cualquier cuota de poder a los liberales.

El otro concepto que se desprende del mensaje de Medinski - $y$ aquí habla como el historiador oficial del Kremlin que él encarna- es una idea insustancial de reconciliación nacional, la idea de que lo que los rusos deben aprender de la Revolución es la necesidad de ceder y reconciliarse. En esta cruzada la iglesia rusa también está haciendo su parte. La iglesia es muy rica y poderosa en Rusia y está desarrollando una gran labor para conmemorar a sacerdotes victimizados por la Revolución. Han abierto una Iglesia de la Reconciliación en el Monasterio Sretensky, que, simbólicamente en este revoltijo posmoderno, está ubicada al costado de la Lubianka, histórica sede de la KGB.

El gobierno ruso también anunció que está planificando la construcción de un monumento de reconciliación nacional. El lugar en que va a ser erigido fue anunciado de manera extraña antes de iniciarse su construcción, que de seguro se hará de manera expedita antes del 7 de noviembre y será horrible. El lugar escogido para el monumento fue, provocativamente, Crimea. No sólo Crimea, sino el punto donde se encuentra el puente que une Crimea y Rusia. Por supuesto, la justificación es que la guerra civil concluyó en Crimea. Ahí fue donde el Ejército Blanco finalmente se desbandó; por lo tanto, se trata de un lugar simbólico para la reconciliación. Pero creo que se trata claramente de un proyecto nacionalista para reivindicar Crimea, "la tierra por la que luchamos, por la que vertimos nuestra sangre, nuestra tierra".

Quiero volver al tema de la memoria colectiva. Básicamente, lo que desearía plantear como tema para la discusión es que Rusia realmente no tiene un pasado que rescatar a partir de la Revolución. Tiene una gran confusión respecto de su historia revolucionaria, acerca de lo que debiera hacer con ella y acerca de los valores y las lecciones que debiera extraer de ella. Producto de lo anterior, los rusos incurren en una serie de actitudes políticas preocupantes, en el sentido de que las encuestas muestran de manera consistente que la mayoría de los rusos anhelan un líder fuerte como Stalin y que piensan que la mayoría de las políticas implementadas por Stalin estaban justificadas y eran necesarias. Una encuesta que considero especialmente desconcertante fue realizada hace aproximadamente ocho años en tres ciudades. Se le preguntó a la gente lo que pensaban acerca de la Cheka (la policía política 
secreta que fundó Lenin), y el 70 por ciento de los encuestados opinó que ésta había defendido a la sociedad. A pesar de reconocer que alrededor de 10 a 20 millones de personas inocentes habían sido asesinadas por la política de terror de la NKVD, ${ }^{3}$ seguían pensando que "defendía la sociedad". En un programa de debate televisivo en el cual se discutió acerca de la colectivización, algunos panelistas relataron los terribles costos que supuso en términos de hambruna y otros males, pero luego se realizaron encuestas para ver qué pensaba la gente, y resulta inverosímil que, pese a toda la evidencia entregada respecto de los costos de la colectivización, más del 90 por ciento de los televidentes pensaba que la colectivización había sido necesaria.

¿Será esto una especie de patología rusa, de veneración de la violencia estatal? No lo creo, no está en su ADN. Pienso que debemos reflexionar sobre lo que les he hablado en esta charla: la construcción de mitos. En Rusia, las personas no han tenido acceso a una investigación histórica libre, no ha existido tampoco el espacio para la discusión y el debate histórico en los medios estatales ni en la televisión. El público puede acceder a información, pero tiene que procurársela por su propia cuenta. La mayoría no lo hace. Prefiere leer los periódicos, mirar la televisión, y lo que reciben es pura propaganda del Kremlin.

Lo que está en juego es el poder de la memoria oficial o de la construcción de mitos; la capacidad de suprimir la memoria colectiva, memoria que se forma en una sociedad con libertad de expresión y libertad de reunión, sin censura respecto a lo que la gente puede decir en términos de investigación histórica. Esto significa que la esfera de la memoria individual, lo que las personas recuerdan por su experiencia directa o por las ideas que han recibido de sus familias y de sus raíces en la sociedad, no posee una estructura adecuada, una estructura conceptual donde pueda ser encajada. Disponen de un par de autores, como Solzhenitsyn y otros a los que podrán acceder, pero, fuera de eso, la estructura que han recibido proviene de esta poderosa máquina creadora de mitos. Éste es el verdadero problema de Rusia, que recién comienza, si es que ha comenzado: cómo llegar a cierto acuerdo con su pasado revolucionario.

${ }^{3}$ Abreviatura para el Comisariado del Pueblo para Asuntos Internos, departamento de seguridad interior de la URSS, que siguió a la Cheka y más tarde se convertiría en la KGB. Entre otros asuntos, manejaba los gulag, campos de prisioneros políticos (n. del e.). 


\section{ALGUNAS PREGUNTAS DEL PÚBLICO}

Pregunta: Hay un momento, entre febrero y octubre de 1917, en que los bolcheviques toman el poder y hay una cierta ebullición democrática. Está la Duma, que ha sido elegida, hay un gobierno provisorio liberal muy preocupado de elaborar una constitución y de juntar una asamblea constituyente para que esa constitución se escriba, hay una inquietud democrática profunda y real. Es la pequeña semilla de una democracia, que rápidamente es aplastada por los bolcheviques. ¿No hay allí algo que los rusos de hoy podrían rescatar, como una forma de construir una memoria colectiva un poco más democrática, más constitucional?

Orlando Figes: Sinceramente, no creo que haya hoy en Rusia alguna reflexión importante en torno a lo que pudiera constituir una base fundacional del liberalismo y constitucionalismo. Una reflexión sobre los eventos de febrero de 1917 podría ser, efectivamente, un punto de partida para esta reflexión. Los historiadores conciben el período entre febrero y octubre de 1917 definitivamente como un momento con muchas potencialidades democráticas. Se podría caracterizar la instauración del gobierno provisional como un golpe de Estado parlamentario en una situación de caos para establecer algún tipo de orden antes de que sea elegida una asamblea constituyente. Pero, en cierto sentido, la forma en que tomó el poder fue ilegítima, aunque luego trató de basar su legitimidad en la Duma. Pero ése es el dilema de todas las revoluciones: no se puede tomar el poder en una situación revolucionaria sin ensuciarse las manos. Aunque ese origen, a su vez, daña tu legitimidad. La posibilidad real en términos de un legado liberal, constitucional, en rigor, no es la Duma, sino la asamblea constituyente, de no haber sido clausurada a la fuerza por los bolcheviques el 5 y 6 de enero. El centenario de ese acontecimiento a comienzos del año que viene ${ }^{4}$ probablemente pase desapercibido, pero fue el primer y último momento en el cual Rusia tuvo un Parlamento verdaderamente democrático.

Ahora bien, creo que hay un problema mayor respecto de ese tema si analizamos lo que sucedió en 1917 y que explica por qué el liberalismo colapsa tan rápido. Tiene que ver con la debilidad, en general, del liberalismo en Rusia. Los kadetes, es decir, los demócratas constituciona-

\footnotetext{
${ }^{4}$ Figes se refiere a 2018 (n. del e.).
} 
listas, son el principal partido liberal y dominan la primera Duma, pero no son realmente un partido liberal en el sentido occidental. Son un partido radical. Cuentan entre sus dirigentes con numerosos profesores, abogados, profesionales, pero apoyan un programa agrario socialista en la primera Duma, que promueve la expropiación obligatoria de las tierras. Lo único que separa a los kadetes de los socialistas es que los primeros quieren compensar a los terratenientes por la expropiación de sus tierras. Se trata de una importante distinción. Los liberales rusos tenían un lema muy decidor: "Sin enemigos a la izquierda". Por ende, apuntan a formar un frente popular y eso fue un gran problema para el gobierno provisional. ¿Cómo constituir un gobierno con los liberales y tener una base popular al mismo tiempo? Se probó imposible. Las divisiones eran tan profundas que resultó imposible formar un gobierno democrático que integrara a la vez elementos liberales de la intelligentsia - que no fueran de la clase obrera o campesinos - y a los partidos socialistas. No es que el gobierno provisional fuera suprimido rápidamente en octubre de 1917. Es el hecho de que en marzo de 1917 el socialismo se ha vuelto hegemónico. El concepto de socialismo tiene una popularidad universal, como la palabra democracia. Es una situación hegemónica que nadie puede cuestionar. Los kadetes lo intentan, pero en las elecciones de septiembre de la Duma, donde contaban con el apoyo de profesores y abogados en las principales ciudades, sólo obtienen el dos por ciento. Porque no se pueden ganar elecciones a no ser que se utilice un lenguaje socialista. Por lo tanto, éste es el problema y es sintomático de las divisiones existentes.

Por supuesto, el socialismo ha muerto en Rusia. En sus primeros años Putin realizó una política al estilo de Stolypin ${ }^{5}$, que es una especie de conservadurismo liberal, en el cual, por un lado, se apoya la monarquía y, por otro, se avanza hacia reformas políticas que separan a la oposición revolucionaria de los elementos más liberales de la sociedad y se resuelve el problema de la tenencia de tierras mediante el loteo y la privatización. Es una suerte de liberalismo, si se quiere. Entonces, en sus primeros años de gobierno, Putin veía en Stolypin un posible

${ }_{5}^{5}$ Piotr Arkádievich Stolypin (1862-1911) fue el tercer primer ministro del Imperio Ruso, entre 1906 y 1911. Es considerado un monarquista que, con visión de Estado, fue consciente de que ciertas reformas, como la agraria, eran necesarias para modernizar el imperio y controlar los espíritus revolucionarios. 
modelo para Rusia pero no duró mucho. No creo que hoy nadie esté preocupado de Stolypin; sin embargo, su concepto de nacionalismo es relevante y la idea de hacer de Rusia una gran potencia, pregonada en numerosas ocasiones por Stolypin, sigue siendo parte del discurso conservador de Putin. Creo que el régimen ha abandonado cualquier idea de reforma; no le interesa el reformismo, menos aún el reformismo económico, pues eso alienaría su base de poder tecnocrático. Por lo tanto, precisamente debido a este pasado revolucionario, no creo que se pueda rescatar mucho del legado liberal en Rusia.

Pregunta: ¿Todas las revoluciones necesitan un mito o fue esto un fenómeno particular de la Revolución Rusa?

Orlando Figes: Pienso que sí, porque, por definición, todas las revoluciones son ilegítimas, por ende, necesitan un mito fundacional que las legitime. La Revolución de 1688 en Inglaterra se transformó en la Gloriosa Revolución en 1689, un año después de que se estableciera la soberanía parlamentaria. La Revolución Francesa fabrica su propia mitología desde el primer día y la Revolución Rusa hizo lo mismo. Por lo tanto, es probable que todas las revoluciones lo hagan. Pienso que la mitología de la Revolución Rusa fue especialmente potente debido a la cultura religiosa de Rusia y al poder del simbolismo político. Tomemos, por ejemplo, el simbolismo de la estrella roja. Ya en 1918 un editorial del periódico Pravda señala que la estrella roja representa a Pravda, diosa de la verdad y la justicia que lucha contra el mal. Así, los símbolos de la Revolución se superponen a esta especie de iconografía religiosa, a este folclor.

Pregunta: En este preciso momento, el presidente y el secretario de mi centro de alumnos en la Escuela de Derecho están viajando al encuentro organizado por la Federación Mundial de la Juventud Democrática. Éste no tendrá lugar en Moscú, sino en Sochi y Vladivostok, pero naturalmente el viaje no sería completo si no incluyera una visita al mausoleo del camarada Lenin. La pregunta es si usted tiene una explicación de por qué la Revolución es aún tan llamativa, tal vez no para la población rusa, pero sí para la izquierda en general en todo el mundo.

Orlando Figes: Creo que lo que persiste es el romanticismo de la Revolución, son las posibilidades que abre. No sé lo que sucede en Chile, pero en el Reino Unido han aparecido algunos libros escritos por viejos autores izquierdistas y trotskistas, como Tariq Ali, China Míevi- 
lle y algunos autores de novelas fantásticas, y todos se refieren al potencial del pueblo en 1917. Saben lo que sucedió, ya no siguen negando que millones murieron producto del terror de las políticas soviéticas, pero siguen diciendo "sí, pero octubre" o, "sí, pero todo podría haber sido diferente", o "la culpa es de Stalin, no quizás de Lenin"... El romanticismo de la revolución es decir que no podemos descartar la revolución como una posibilidad, no debe despreciarse la energía que puede crear, es reaccionario negar esa posibilidad. Por lo tanto, existe esta simpatía romántica por la revolución que está particularmente ligada a Rusia, debido a este otro gran mito, que también podría ser tema para otra conferencia completa: el mito del alma rusa. Puede que los rusos estén rezagados en el plano material, pero tienen algo especial, que es una misión moral superior, cualidades espirituales, la creencia en el colectivismo, algo que ha sido definido de muchas formas distintas. Esta idea del alma rusa encarnada por Gógol y los eslavófilos que lo siguieron y se convirtió en parte del atractivo internacional de la Revolución, la idea de que la Tercera Internacional salvará a la humanidad, la misión especial que Rusia tiene en el mundo. Por lo tanto, pienso que parte del romanticismo de la izquierda sobre la Revolución es un romanticismo sobre Rusia en general. Los rusos son un pueblo elegido, que posee una suerte de antídoto contra la decadencia, la corrupción y el materialismo del capitalismo occidental. EP 
